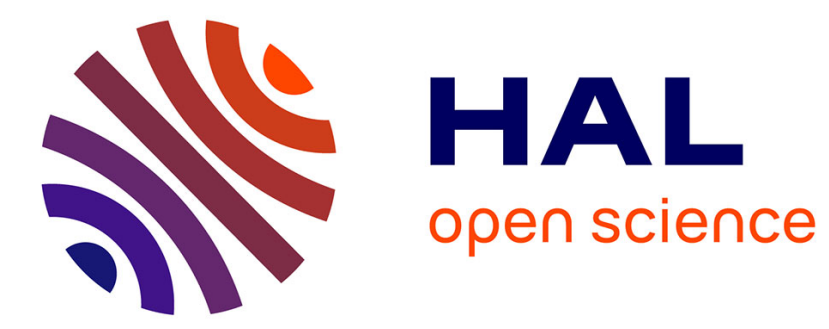

\title{
A case of epistaxis
}

Alexandre Debelmas, Sophie Lanciaux, Thomas Schouman

\section{To cite this version:}

Alexandre Debelmas, Sophie Lanciaux, Thomas Schouman. A case of epistaxis. Journal of Stomatology, Oral and Maxillofacial Surgery, 2017, 10.1016/j.jormas.2017.08.002 . hal-01592657

\section{HAL Id: hal-01592657 https: / hal.sorbonne-universite.fr/hal-01592657}

Submitted on 25 Sep 2017

HAL is a multi-disciplinary open access archive for the deposit and dissemination of scientific research documents, whether they are published or not. The documents may come from teaching and research institutions in France or abroad, or from public or private research centers.
L'archive ouverte pluridisciplinaire HAL, est destinée au dépôt et à la diffusion de documents scientifiques de niveau recherche, publiés ou non, émanant des établissements d'enseignement et de recherche français ou étrangers, des laboratoires publics ou privés. 
Elsevier Editorial System(tm) for Journal of Stomatology Oral and Maxillofacial Surgery

Manuscript Draft

Manuscript Number: REVSTO-D-17-00025R1

Title: A case of epistaxis

Article Type: Case Report

Keywords: Epistaxis; internal maxillary artery; descending palatine artery; pseudo aneurysm; endovascular management

Corresponding Author: Mr. Alexandre Debelmas, M.D.

Corresponding Author's Institution: Hôpital universitaire PitiéSalpêtrière, APHP

First Author: Alexandre Debelmas, M.D.

Order of Authors: Alexandre Debelmas, M.D.; Sophie Lanciaux, MD; Thomas Schouman, MD, PhD

Abstract: The authors report a case of epistaxis in a 74-year-old male patient. His recent medical history documented recurrent nasal bleeding and a Le Fort 1 osteosynthesis 3 weeks before admission to our unit. A CT scan revealed a left descending palatine artery pseudoaneurysm in the left maxillary sinus, that was successfully embolized.

Pseudoaneurysms of the internal maxillary artery and its branches are rare life-threatening complications. This diagnosis should be considered when confronted to recurrent head and neck bleeding, especially in a context of recent maxillo-facial trauma or surgery. Embolization should rapidly be implemented. 


\section{A case of epistaxis}

Debelmas A, Lanciaux S, Schouman T

Debelmas A, MD (Corresponding author)

AP-HP, Hopital Pitie-Salpetriere, Service de chirurgie maxillo-faciale, Paris, F-75013, France; UPMC Univ Paris 06, F-75005, Paris, France

Mail: Alexandre.debelmas@ hotmail.fr

Tel: +33633318610

Lanciaux S, MD

AP-HP, Hopital Pitie-Salpetriere, Service de chirurgie maxillo-faciale, Paris, F-75013, France; UPMC Univ Paris 06, F-75005, Paris, France

Schouman T, MD PhD

AP-HP, Hopital Pitie-Salpetriere, Service de chirurgie maxillo-faciale, Paris, F-75013, France 


\section{*.. Manuscript}

Click here to download .. Manuscript: abstract-manuscript-legends CE1.docx

1

2

3

4

5

6

7

8

9

10

11

12

13

14

15

16

17

18

19

20

21

22

23

24

25

26

27

28

29

30

31

32

33

34

35

36

37

38

39

40

41

42

43

44

45

46

47

48

49

50

51

52

53

54

55

56

57

58

59

60

61

62

63

64

65

\section{A case of epistaxis}




\begin{abstract}
The authors report a case of epistaxis in a 74-year-old male patient. His recent medical history documented recurrent nasal bleeding and a Le Fort 1 osteosynthesis 3 weeks before admission to our unit.

A CT scan revealed a left descending palatine artery pseudoaneurysm in the left maxillary sinus, that was successfully embolized.

Pseudoaneurysms of the internal maxillary artery and its branches are rare life-threatening complications. This diagnosis should be considered when confronted to recurrent head and neck bleeding, especially in a context of recent maxillo-facial trauma or surgery. Embolization should rapidly be implemented.
\end{abstract}




\section{Case presentation:}

A 74-year-old male patient was admitted to the emergency department with left-side epistaxis. Bleeding rapidly resumed, despite left anterior nasal packing, with expulsion of blood clots and with active bleeding through the left vestibular surgical wound.

The patient's recent medical history included surgical osteosynthesis of a Le Fort 1 fracture, 3 weeks before admission.

A CT scan revealed a high density mass in the left maxillary sinus surrounded with a lower density component, compatible with a pseudo aneurysm (PA). The angioscan images at a venous phase were compatible with an aneurysm sac (Figure 1 and 2).

Catheterization of the external carotid was decided to further assess the origin of the bleeding and proceed with embolization (Figure 3). A large pseudoaneurysm was observed on the descending palatine artery (one of the branches of the third portion of the internal maxillary artery) and was embolized through a femoral approach.

Cases of PA have been reported following orthognathic surgery, or Le Fort and mandibular condyle fractures $[\mathbf{1}-\mathbf{4}]$.

Such lesions are rare, nevertheless physicians should consider this diagnosis when facing recurrent or persistent bleeding, even in case of late post-surgical onset. Indeed, rupture of the aneurysm sac can cause a life-threatening hemorrhage. 


\section{Legend:}

Figure 1: axial section of the midface CT scan without injection, showing a heterogeneous left maxillary hemosinus.

Figure 2: axial section of the midface angioscan, at a venous phase, showing the aneurism sac in the left maxillary sinus.

Figure 3: arteriography of the left external carotid network. The pseudo-aneurysm is located on the left descending palatine artery, which is a branch of the third portion of the left internal maxillary artery. 


\section{References}

[1]. Gold M. Partially Thrombosed Internal Maxillary Pseudoaneurysm after Gunshot Wound. Craniomaxillofacial Trauma Reconstr 2016;9:335-7.

[2]. Nastro Siniscalchi E, Catalfamo L, Pitrone A, Papa R, Famà F, Lo Giudice G, et al. Traumatic Pseudoaneurysm of the Internal Maxillary Artery: A Rare Life-Threatening Hemorrhage as a Complication of Maxillofacial Fractures. Case Rep Med 2016;2016:9168429.

[3]. Alonso N, de Oliveira Bastos E, Massenburg BB. Pseudoaneurysm of the internal maxillary artery: A case report of facial trauma and recurrent bleeding. Int J Surg Case Rep 2016;21:63-6.

[4]. Hennus MP, Speleman L. Internal Maxillary Artery Pseudoaneurysm: A Near Fatal Complication of Seemingly Innocuous Pharyngeal Trauma. Case Rep Crit Care 2011;2011:241375 


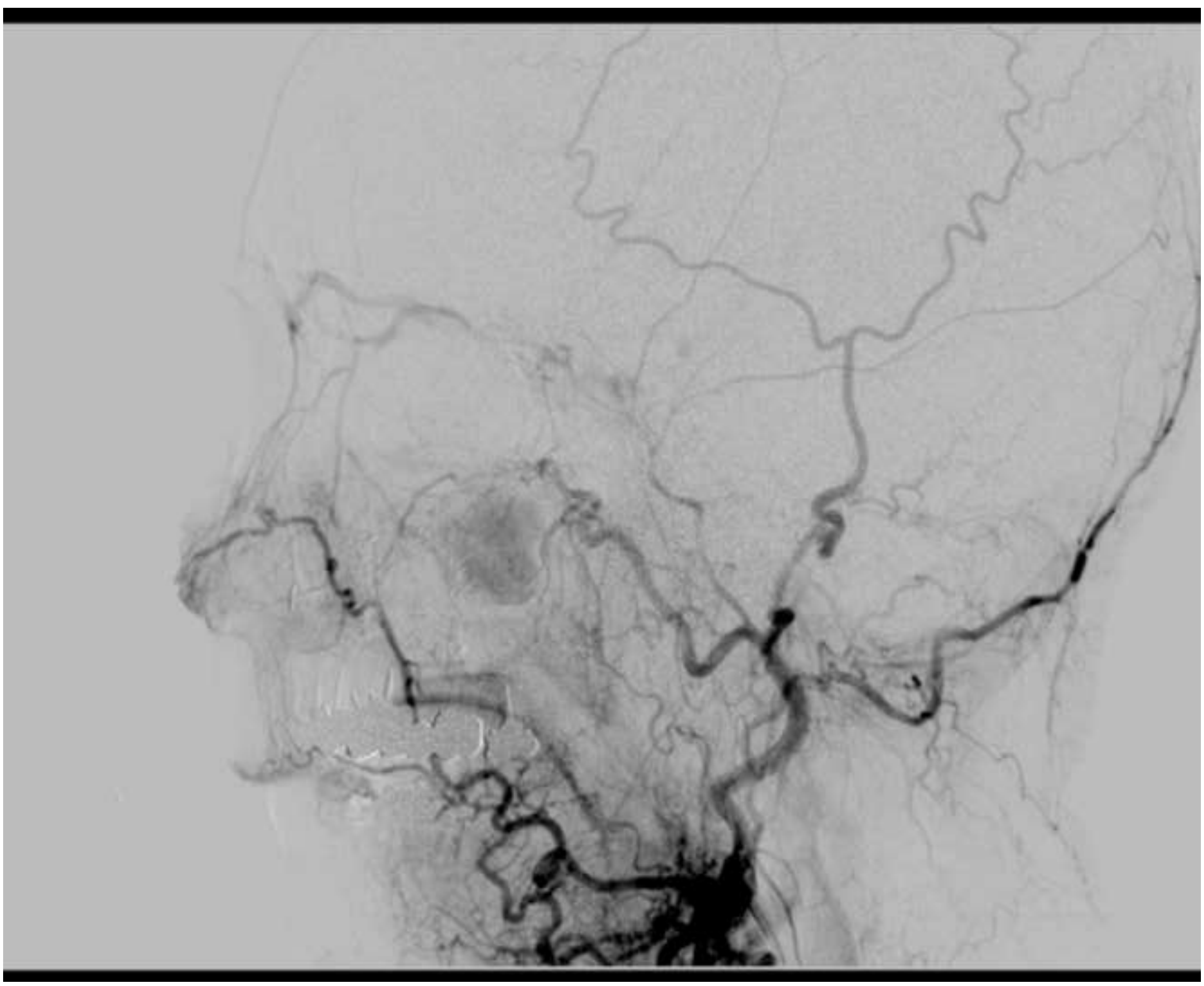




\section{*.. Manuscript}

Click here to download .. Manuscript: abstract-manuscript-legends.docx

1

2

3

4

5

6

7

8

10

11

12

13

14

15

16

17

18

19

20

21

22

23

24

25

26

27

28

29

30

31

32

33

34

35

36

37

38

39

40

41

42

43

44

45

46

47

48

49

50

51

52

53

54

55

56

57

58

59

60

61

62

63

64

65

\section{A case of epistaxis}




\section{Case presentation:}

A 74-year-old male patient was admitted to the emergency department with a left-side epistaxis. Bleeding rapidly resumed, despite a left anterior nasal packing, with expulsion of blood clots and with active bleeding through the left vestibular surgical wound.

The patient's recent medical history included a surgical osteosynthesis of a Le Fort 1 fracture, 3 weeks before admission.

A CT scan revealed a high density mass in the left maxillary sinus surrounded with a lower density component, compatible with a pseudo aneurysm (PA). The angioscan images at a venous phase were compatible with an aneurysm sac (Figure 1 and 2).

Catheterization of the external carotid was decided to further assess the origin of the bleeding and proceed with embolization (Figure 3). A large pseudoaneurysm was observed on the descending palatine artery (one of the branches of the third portion of the internal maxillary artery) and was embolized through a femoral approach.

Cases of PA have been reported following orthognathic surgery, or Le Fort and mandibular condyle fractures (1-4).

Such lesions are rare, nevertheless physicians should consider this diagnosis when facing recurrent or persistent bleeding, even in case of late post-surgical onset. Indeed, rupture of the aneurysm sac can cause a life-threatening hemorrhage. 


\section{Legend:}

Figure 1: axial section of the midface CT scan without injection, showing a heterogeneous left maxillary hemosinus.

Figure 2: axial section of the midface angioscan, at a venous phase, showing the aneurism sac in the left maxillary sinus.

Figure 3: arteriography of the left external carotid network. The pseudo-aneurysm is located on the left descending palatine artery, which is a branch of the third portion of the left internal maxillary artery. 


\section{References}

1. Gold M. Partially Thrombosed Internal Maxillary Pseudoaneurysm after Gunshot Wound. Craniomaxillofacial Trauma Reconstr 2016;9:335-7.

2. Nastro Siniscalchi E, Catalfamo L, Pitrone A, Papa R, Famà F, Lo Giudice G, et al. Traumatic Pseudoaneurysm of the Internal Maxillary Artery: A Rare Life-Threatening Hemorrhage as a Complication of Maxillofacial Fractures. Case Rep Med 2016;2016:9168429.

3. Alonso N, de Oliveira Bastos E, Massenburg BB. Pseudoaneurysm of the internal maxillary artery: A case report of facial trauma and recurrent bleeding. Int J Surg Case Rep 2016;21:63-6.

4. Hennus MP, Speleman L. Internal Maxillary Artery Pseudoaneurysm: A Near Fatal Complication of Seemingly Innocuous Pharyngeal Trauma. Case Rep Crit Care 2011;2011:241375. 


\section{Response to reviewers}

Dear reviewers of the journal of Stomatology, Oral and Maxillofacial Surgery,

The manuscript's English language has been revised, as asked. We hope that the paper, in its present form will fulfill your expectations.

Best Regards,

Alexandre Debelmas 